\title{
Glossary and note on Shetland dialect
}

Bere a kind of barley

Bigg to build

Böd a fisherman's booth or hut

Delling digging using traditional Shetland method

Dyke stone wall

Haaf deep-sea fishery

Hairst harvest

Hap small hand-knitted shawl

Howdie untrained midwife

Kishie basket made of straw and carried on the back or on a pony

Plantiecrue stone enclosure to protect small plants

Peerie small

Roo to pluck wool from a Shetland sheep

Runrig a form of land use whereby land is parcelled out in individual and often discontinuous strips or rigs

Scattald common pasture attached to a township

Skekkler a guiser clad in a suit of straw

Skroo corn stack

Spencer under-vest

Trow fairy or 'little folk' with magical properties

Voar spring

\section{Note on Shetland dialect}

Where appropriate, quotations from oral history interviews have been reproduced as they were transcribed from the tapes, in Shetland dialect. Oral history interviews conducted by the author were transcribed by the author into standard English and are reproduced as such. 